\title{
Eça de Queirós e a recepção da crítica literária brasileira
}

\author{
Cristiane Navarrete Tolomei ${ }^{1}$
}

\begin{abstract}
RESUMO: Este texto consiste em analisar a trajetória da crítica brasileira sobre a vida e a obra de José Maria Eça de Queirós (1845-1900), tomando como base a primeira crítica brasileira realizada por Machado de Assis (1839-1908) publicada nas páginas da revista O Cruzeiro (1878) e perpassando por quatro dos principais críticos brasileiros de Eça: Vianna Moog (1906-1988), Álvaro Lins (1912-1970), Paulo Cavalcanti (1915-1995) e Arnaldo Faro (? - ).
\end{abstract}

ABSTRACT: This text consists on analyzing the trajectory of the Brazilian criticisms concerning to the life and work of José Maria Eça de Queirós (1845-1900). The starting point of such trajectory was the first Brazilian critical work made by Machado de Assis (1839-1908), published on four pages in $O$ Cruzeiro magazine (1878), besides approaching to four of the main Eça's Brazilian critics: Vianna Moog (1906-1988), Álvaro Lins (1912-1970), Paulo Cavalcanti (1915-1995) and Arnaldo Faro (? -).

PALAVRAS-CHAVE: Eça de Queirós; crítica; recepção; Brasil.

KEYWORDS: Eça de Queirós; criticism; reception; Brazil.

Eça de Queirós produto do seu tempo. Essa afirmação mais do que apropriada é merecida, pois, melhor do que ninguém soube realizar um retrato fiel da sociedade portuguesa da segunda metade do século XIX, denunciando os vícios e o provincianismo que nela predominavam. Porém, embora tenha sido um sujeito representativo da época em que viveu e produziu literatura, Eça de Queirós transgrediu o seu tempo, atingindo a atualidade de forma vivaz, fato que lhe permite ser até hoje centro de discussão da crítica literária brasileira. Beatriz Berrini, uma das maiores representantes da crítica queirosiana no Brasil, considera Eça "um artífice que ignorou o fluir do tempo e tem mais a ver com a eternidade". ${ }^{2}$

A atenção dada à obra queirosiana, como é sabido, partiu da primeira e mais polêmica crítica realizada no Brasil. Efetuada por Machado de Assis, em 16 de Abril de 1878, nas páginas de $O$ Cruzeiro, o escritor brasileiro criticou a superficialidade de Eça na

\footnotetext{
${ }^{1}$ Doutoranda em Estudos Comparados de Literaturas de Língua Portuguesa, FFLCH-USP. Pesquisa: $A$ crítica literária brasileira sobre Eça de Queirós. E-mail: cntolomei@yahoo.com.br

${ }^{2}$ Comentário de Beatriz Berrini retirado da Conferência "Vida efêmera/arte perene", proferida no dia 26 de Setembro de 2000 em Brasília e inserida no projeto do Instituto Camões intitulado "Eça de Queirós - Pontos de Olhar".
} 
construção de suas personagens, principalmente com relação à Luísa de O Primo Basílio (1878).

Após a iniciativa de Machado de Assis, a crítica literária brasileira progressivamente voltou seus olhares à vida e à obra de Eça de Queirós e, que ao longo do século XX, receberam leituras diversas, "de modo que a popularidade obtida no Brasil nem sempre resultou de uma compreensão mais completa" (CANDIDO, 2000, p. 17).

A crítica literária da primeira metade do século XX seguia uma linha historiográfica cultivada anteriormente por críticos como Sílvio Romero, José Veríssimo e Araripe Júnior. Destacam-se, para este estudo, dois críticos que desenvolveram leituras críticas sobre a vida e a obra de Eça de Queirós partindo desse foco crítico: Vianna Moog (1906-1988) e Álvaro Lins (1912-1970).

Wilson Martins, em A crítica literária no Brasil (1983), também insere Vianna Moog e Álvaro Lins na linhagem histórica, porém, em seguida, apresenta esses críticos entre dois vieses, o da linhagem histórica e o da linhagem impressionista. Esta última, despontada na França no fim do século XIX e princípio do século XX, restringia-se à notação das impressões que a obra instigava em seu leitor.

De um modo geral, a crítica literária, a partir de 1930, foi uma das mais produtivas, em conseqüência da industrialização que possibilitou a abertura de novos pensamentos tanto filosóficos quanto artísticos, corroborando, ao mesmo tempo, ao aumento de nossa consciência crítica. Dessa forma, por meio da imprensa e do livro, foram moldados conceitos e métodos, partindo da historiografia literária, da crítica valorativa e do ensino das letras no Brasil.

Dentro desse cenário encontra-se Vianna Moog com seu livro Eça de Queirós e o Século XIX (1938), em que centralizou seu estudo na realização da biografia de Eça de Queirós a partir de um caráter romanceado, isto é, a figura do escritor foi construída pelo mesmo processo que se constrói uma personagem literária: "Parece uma alma que se achou desde criança hostilizada e que se refugiou em si mesma, como estas flores que fecham o cálice quando são tocadas. Chama-se José Maria Eça de Queiroz.” (1938, p. 23-24).

Verificou-se que o crítico lançou mão de uma abordagem biográfica embasada nos textos ficcionais de Eça, o que nos remete à questão: Eça fez autobiografia? Como é sabido, Eça, em nenhum momento, deixou transparecer essa aproximação entre a sua vida e as vidas de suas personagens, então, pode-se, de antemão, levantar um primeiro problema no 
texto de Moog - porém, não descartando seu talento e pioneirismo empreendido num período em que se iniciava um gradativo movimento crítico.

Nos anos 30, o saber literário estava em harmonia com o saber da história literária e conhecer um escritor era, conseqüentemente, saber em detalhes sua biografia. Esse foi o trajeto percorrido por Moog, uma obra que surgiu com o objetivo de apresentar o "verdadeiro" Eça de Queirós. A preocupação sobre o verídico era tanta que Moog esclareceu no "Prefácio" do seu Eça de Queiroz e o Século XIX que a tentativa de seguir os passos reais do autor possibilitou a ele apresentar fotografias que tivessem um valor histórico e de verdade sobre os seus argumentos.

Vianna Moog, preocupado com a veracidade de seu texto, construiu um Eça totalmente inserido em seu tempo e voltado aos movimentos ideológicos do final do século XIX. Pretendia-se com isso demonstrar que o homem da segunda metade do século XIX permanecia atual em pleno século $\mathrm{XX}$, fazendo predominar suas características "contemporâneas": "Resistem sobranceiros a todas as investidas, como se os anos nada tivessem podido contra sua atualidade e sedução. Para nos libertarmos deles só há um caminho a seguir: escrever-lhes a biografia." (1938, p. 5-6).

$\mathrm{Na}$ crítica queirosiana de Moog depreendem-se dois momentos: um primeiro momento em que o crítico perpassou seu estudo por um viés ficcional, abandonando o caráter documental da biografia de Eça; e, um segundo momento, em que Moog iniciou um processo de reflexão ideológica da literatura e da obra queirosiana. Assim, apesar de tomar um caminho distante do que ocorre atualmente nos textos biográficos, Vianna Moog, por sua iniciativa e visão interpretativa dos fatos da vida de Eça renovou, em 1938, o método crítico utilizado por seus antecessores.

No final da década de 30 e início de 40 surgiu Álvaro Lins na crítica literária brasileira nas páginas do Correio da Manhã, conciliando a sua vocação crítica ao conhecimento profundo da moderna teoria literária, ele escreveu, além de crítica jornalística, monografias, ensaios e livros que abrangiam estudos tanto sobre a literatura brasileira quanto a literatura portuguesa.

Álvaro Lins defendia uma crítica que tinha duas faces diferentes, a interpretação e o julgamento, em que a segunda seria o complemento da primeira. Sua crítica passou por um historicismo jornalístico, desenvolvendo uma posição humanista, em sua maioria ativa em vez de reflexiva, seguindo para um cunho impressionista. Para ele, a crítica brasileira 
começou a desenvolver a criação de formas pesquisadas, o que resultou em um estilo coletivo.

A presença da linhagem impressionista na obra crítica de Álvaro Lins está marcante no seu texto História literária de Eça de Queiroz, de 1939. Embora, no ano de publicação o crítico se encaixasse na linhagem histórica, foi possível identificar aspectos impressionistas pelo fato de Álvaro Lins não esconder suas impressões sobre a vida e a obra de Eça. O seu texto rodeia o debate entre um Eça doutrinário e um Eça artista: "A sua biografia é a história do conflito que o explica: conflito entre o artista e o homem. $\mathrm{O}$ artista que procurava ultrapassar o tempo e a época, o homem que tendia a ligar-se aos problemas do seu século [...]" (1939, p. 15).

O que está sendo relatado por Álvaro Lins nesse trecho é que Eça superou a sua escola e passou a se preocupar com a obra de arte, que para o autor português era o local onde se podiam encontrar as verdades humanas e as verdades da vida. Assim, o romance queirosiano posiciona-se tanto como uma obra literária quanto como um documento humano e social de seu país e de sua época.

$\mathrm{O}$ início do realismo português tem como marco a obra $O$ Crime do Padre Amaro (1876), mas essa inovação literária culminou, principalmente, em Os Maias (1888) em que Eça atingiu seu objetivo de representar a sociedade portuguesa do século XIX (já que não publicou os 12 volumes de Cenas da Vida Portuguesa). Para Álvaro Lins foi nesse romance que o escritor português melhor representou sua personalidade e a sua vivência em Lisboa. Além de Os Maias, o crítico elegeu a Ilustre Casa de Ramires (1900) como uma das principais obras de Eça, destacando de todo o texto a personagem Gonçalo e colocando-o como retrato da imagem de Eça. Em relação a $O$ Mandarim (1879) e $A$ Relíquia (1887), Álvaro Lins enquadrou essas obras como sendo do domínio da fantasia, apoiando-se na realidade para mostrar seus "devaneios mais libertários" (1939, p. 84). Com A Correspondência de Fradique Mendes (1900), o crítico deixou claro que a personagem não representa o escritor, destacando que o criador está distante da criatura. Álvaro Lins afirmou que Eça criou Fradique a partir de um gênero que mescla memórias e novela e, o mais importante, e o que realmente cria essa distância entre Eça e a personagem, é o fato de Fradique ter sido construído com base em amigos de Eça, o que revela uma figura “coletiva". Aproximando-se de Os Maias, Fradique Mendes significou o ato vingativo de Eça contra o seu século, revelando a "miséria social da burguesia" e a "miséria individual dos seus contemporâneos". Para finalizar, Álvaro Lins realizou críticas ferrenhas à obra $A$ 
Cidade e as Serras (1901), assegurando que é um livro de decadência, em que o enredo é inexistente e as personagens "de uma extrema miséria de vida".

Constatou-se, nesse percurso através da crítica queirosiana de Álvaro Lins, que ele não mediu palavras para atacar ou elogiar os textos de Eça, daí a tendência impressionista de suas leituras críticas. Em geral, o crítico conseguiu apresentar ao seu leitor o caráter harmônico da obra queirosiana entre o que é humano e o que é artístico, revelando que o "socialismo" de Eça "foi muito mais um sentimento do que uma idéia".

Diferente de Vianna Moog, Álvaro Lins, apesar da aproximação pela análise ideológica entre os dois, estava distante da perspectiva biográfica que considera a relação entre a vida de Eça e sua obra literária, metodologia adotada por Moog. Álvaro Lins não apresentou uma preocupação exagerada sobre a vida do escritor, o que resultou numa leitura crítica voltada para a discussão de gênero literário, destacando o romance como “aquele que melhor realizaria a sua vocação artística." (1939, p. 91).

$\mathrm{Na}$ crítica literária da segunda metade do século XX, devido à multiplicação dos cursos superiores de Letras, a reflexão sobre o conhecimento literário passou a se distanciar do modelo então vigente. $\mathrm{O}$ centro da crítica literária não mais seria a história da literatura e a biografia dos autores e sim a compreensão do texto literário e o seu valor frente aos leitores.

Num primeiro momento, a experiência - fenomenológica, formalista e estruturalista - estava em voga nessa época no Brasil, influenciada pelo pensamento estético de Husserl, Hartmann e Ingarden, das idéias críticas de Roland Barthes, das teorias de Claude LéviStrauss, Michel Foucault, Jacques Lacan, Louis Althusser e da lingüística de Roman Jakobson.

Num segundo momento, a atenção dada pela crítica seria às relações entre a obra e o leitor. Embasada na Estética da Recepção de Hans Robert Jauss e de Wolfgang Iser, essa metodologia crítica propôs elaborar um modelo estético de leitura literária, revelando que o sentido de uma obra se forma por intermédio de uma história dos modelos de leitura. No Brasil surgiram muitos adeptos a essa tendência crítica, entre eles destacam-se dois críticos ecianos: Paulo Cavalcanti (1915-1995) e Arnaldo Faro (?-).

Paulo Cavalcanti, no final da década de 50, publicou Eça de Queiroz agitador no Brasil, em que desenvolveu um tema polêmico sobre Eça e o Brasil, que foi o da reação dos brasileiros, em desagravo a D.Pedro II pelas "ofensas" que sofrera na revista portuguesa, organizada por Eça de Queirós e Ramalho Ortigão, As Farpas, sobre a visita do Imperador 
a Portugal em 1871. O estudo do crítico está baseado em dois artigos, ambos em forma de cartas, que foram publicados em 1872, uma dirigida ao imperador e a outra ao presidente da Província de Pernambuco.

O que torna o texto de Paulo Cavalcanti fundamental, num primeiro momento, na crítica literária brasileira sobre Eça é a inovação de pesquisar a contrapartida brasileira com relação aos acontecimentos de Pernambuco; e, num segundo momento, em realizar, exaustivamente, levantamento de livros, jornais e manuscritos da época que comprovassem a veracidade dos fatos. Dessa forma, Paulo Cavalcanti percorreu dois caminhos em seu estudo: um que envolveu a sociologia da recepção e, o outro, que envolveu uma preocupação histórico-social: "De um instante para o outro, as doces verrinas de Eça transformaram-se em acres censuras aos Brasileiros, fossem monarquistas ou republicanos;" (s.d., p. 79).

Apesar de realizar uma crítica inovadora para a época, Paulo Cavalcanti não conseguiu abandonar suas impressões em seu estudo, o que resultou em considerações equivocadas. Ele colocou o seu nativismo em primeiro plano e responsabilizou integralmente Eça pelos artigos. O crítico acreditava que o seu trabalho sobre esse acontecimento, lastimável na opinião dos brasileiros, provocaria, apesar das críticas de Eça, o aumento da admiração do Brasil pelo escritor português.

Nesse percurso histórico-social, Paulo Cavalcanti tentou inserir os textos de $A s$ Farpas numa perspectiva de cunho político-econômico, em que descartou a hipótese da linguagem irônica e mordaz pela qual Eça foi aceito no Brasil. Daí o grande "equívoco" desse estudo do crítico, que redirecionou o que seriam crônicas bem-humoradas para textos planfetários. Paulo Cavalcanti esqueceu que n'As Farpas o tom humorístico rodeava todos os assuntos, pois esse era o caráter da revista. Ele confundiu caráter espirituoso por caráter ofensivo, quando, é sabido, que Eça carrega em sua obra a coexistência entre serenidade, equilíbrio, razão e espírito crítico.

Na década de 70, Arnaldo Faro publicou Eça e o Brasil (1977), mantendo a metodologia crítica voltada à recepção anteriormente já adotada por Paulo Cavalcanti. $\mathrm{O}$ texto de Arnaldo Faro encaixa-se dentro de uma tradição historiográfica por apresentar a presença de Eça no Brasil, mantendo uma tradição da linhagem histórica, porém inovando ao reformular o método que seguiam os críticos, principalmente na primeira metade do século XX, quando trouxe para a sua leitura crítica novos dados a respeito de Eça e sua recepção em terras brasileiras. 
Seguindo pelo viés da cultura brasileira, Arnaldo Faro invocou o Rio antigo para iniciar sua leitura sobre Eça. Ele retomou a origem do escritor afirmando que a influência do Brasil em Eça está presente desde a inserção de seu avô, Joaquim José de Queirós, na magistratura brasileira, passando pelo nascimento de seu pai, José Maria de Almeida Teixeira de Queiroz, no Brasil e chegando a sua ama, Ana Joaquina Leal de Barros, que era brasileira.

Arnaldo Faro realizou uma breve apresentação biográfica de Eça até atingir os acontecimentos que tanto Paulo Cavalcanti se empenhou em descrever, a recepção de $A s$ Farpas em Pernambuco. Porém, ao contrário de Paulo Cavalcanti, Arnaldo Faro não concordou com a afirmação que Eça teria satirizado o brasileiro nativo e não o português de “torna-viagem”, conhecido como "o brasileiro" n'As Farpas.

Após expor algumas contradições do texto Eça de Queiroz agitador no Brasil, de Paulo Cavalcanti, Arnaldo Faro parte para o relato sobre a publicação da primeira versão de O Crime do Padre Amaro (1876) na imprensa periódica de São Paulo, especificamente na revista A República das Letras, especializada em assuntos literários e artísticos. Um dos temas publicados, nessa revista, seria a publicação do texto de Eça, que, infelizmente, foi interrompida logo no início da transcrição do segundo capítulo de $O$ Crime do Padre Amaro.

Em seguida, ele iniciou um percurso maior e centralizado sobre a publicação de $O$ Primo Basílio (1878) no Rio de Janeiro, especificamente na Rua do Ouvidor. Arnaldo Faro fez um panorama histórico da cidade carioca, exibindo dados estatísticos, personalidades históricas e artísticas e acontecimentos da época para ilustrar o cenário de recepção da obra do escritor português. Na chegada ao Brasil, O Primo Basílio não passou despercebido e, como foi visto, recebeu severas críticas de Machado de Assis. A sua recepção em solo brasileiro foi polêmica, mas de grande adesão. A repercussão foi tanta que resolveram adaptar o romance para o teatro, fato então inédito com as obras de Eça, que se concretizou pela primeira vez no Rio de Janeiro.

A partir desse momento, repleto de contrafações aos textos de Eça, Arnaldo Faro apresentou a corrida dos editores para conquistar o público brasileiro e iniciou-se um empreendedor movimento de publicação das obras do escritor português devido, exatamente, a toda polêmica causada na recepção de Eça no Brasil: “Assim, portanto, em 1878, quando o êxito do Primo Basílio firma de modo definitivo a reputação literária do seu 
autor, este podia ser lido muito mais facilmente no Brasil do que em Portugal.” (1977, p. 186).

O estudo de Arnaldo Faro, portanto, percorreu a receptividade de Eça no Brasil e constatou um verdadeiro culto ao escritor português. Observa-se que a imagem do escritor teve força expressiva e seus textos repercutiram positivamente tanto para os leitores em geral quanto para a crítica literária.

Dessa forma, pode-se, a partir das leituras críticas de Paulo Cavalcanti e de Arnaldo Faro, verificar que a situação da crítica literária brasileira na segunda metade do século XX atingiu um status de produção científica. Paulo Cavalcanti, embora influenciado por métodos do início do século, resgatou, em textos desconhecidos, a polêmica gerada por artigos publicados em As Farpas. A partir daí, Eça, passou a ter uma maior projeção no Brasil, conseqüência de seu caráter irônico e universalista.

Corroborando com Paulo Cavalcanti, no que diz respeito à recepção de Eça em terras brasileiras, Arnaldo Faro perpetuou a imagem, já enaltecida de Eça, no Brasil. Conseguiu, por meio de sua intensa análise científica, enraizar a figura "sacrossanta" do escritor português. Conseguiu transmitir ao seu leitor um Eça orgulhosamente brasileiro, colocando-o como patrimônio do Brasil. Eça mais do que nunca era admirado e sua imagem fortaleceu-se, não somente pela aproximação entre o escritor português e o Brasil, mas, principalmente, pela regularidade de publicações tanto de sua obra quanto de textos críticos sobre ele.

Enfim, observou-se que na primeira metade do século XX a crítica literária sobre Eça de Queirós no Brasil se restringia às fronteiras da biografia. Tanto Vianna Moog quanto Álvaro Lins participaram de uma mesma tendência crítica, a histórica, o que aproximou, de maneira geral, suas leituras críticas de uma abordagem historiográfica da vida e da obra de Eça. Contudo, divergiam nos aspectos específicos e particulares de suas investigações, pois, enquanto Vianna Moog, na sua biografia interpretativa sobre o escritor português, atingiu um grau de análise simples, mas sugestiva, Álvaro Lins, abandonando a curiosidade biográfica, elaborou em estudo crítico centrado em aspectos parciais da obra partindo de um ponto de vista valorativo que englobasse toda a obra eciana, o que fortaleceu a crítica sobre o escritor português.

Já na segunda metade do século XX, Paulo Cavalcanti e Arnaldo Faro participaram ativamente de uma época em que discutir Eça era, ao mesmo tempo, uma redundância, ou por outro lado, significava novas descobertas. Assim, adeptos pela segunda característica, 
eles efetivamente ajudaram a delimitar a imagem de Eça, que possivelmente é a mesma que temos hoje: a de "um artista para quem a arte devia ser a história do homem" (CAVALCANTI, s.d., p. 20).

Em síntese, durante o século XX a figura eciana percorreu muitos textos, o que resultou num legado literário de Eça em solo brasileiro.

\section{Referências bibliográficas}

CANDIDO, Antonio. Eça de Queirós, passado e presente. In ABDALA, Jr., Benjamin (org.). Ecos do Brasil: Eça de Queirós, leituras brasileiras e portuguesas. São Paulo: Editora SENAC São Paulo, 2000, p. 11-22.

CAVALCANTI, Paulo. Eça de Queiroz agitador no Brasil. Lisboa: Edição "Livros do Brasil”, s.d. FARO, Arnaldo da Costa. Eça e o Brasil. São Paulo: Ed. Nacional, EDUSP, 1977.

LINS, Álvaro. História literária de Eça de Queiroz. 3.ed. Lisboa: Bertrand, 1959.

MACHADO DE ASSIS. Eça de Queirós: O Primo Basílio. In Obra Completa. Rio de Janeiro: 1962. v.3.

MARTINS, Wilson. A crítica literária no Brasil. Rio de Janeiro: Francisco Alves, 1983. v. 1 e 2. MOOG, C. Vianna. Eça de Queirós e o século XIX. Porto Alegre: Ed. da Liv. do Globo, 1938. 